\title{
Análise biomecânica da marcha humana durante o subir e descer escadas
}

\section{Biomechanical analysis of human gait during the up and down stairs}

\author{
1 Luciana Moreira Lessa lucianamlessa@gmail.com \\ 1 Jayme Pereira Gouvêa
}

1 Universidade Federal Fluminense UFF.

\section{Resumo}

Subir e descer degraus são atividades que absorvem maior grau de dificuldade, principalmente quando se trata de um indivíduo com alterações do sistema musculoesquelético, como fraturas no membro inferior. Diante do problema exposto, este estudo tem como objetivo analisar a marcha humana durante o subir e descer de escada de um indivíduo saudável, para indicar que parâmetros serão utilizados e como serão obtidos para a aplicação em próteses de membros inferiores. Foram analisados, a partir da cinemetria, padrões cinemáticos do movimento, como posição e valores angulares dos segmentos corporais durante a marcha, que foram inseridos em um algoritmo em ambiente Matlab. Foi possível calcular as forças de reação do solo, mostrar a porcentagem do ciclo da marcha em cada instante, identificar os períodos, tarefas e fases assim como analisar os movimentos de flexão e extensão realizados. Os resultados apresentados sugerem que, no desenvolvimento de uma prótese, é preciso se preocupar tanto com o calcanhar quanto com a frente do pé, pois ela também recebe muito peso do corpo durante o subir e descer de degraus, e que, igualmente à fase de apoio, a fase de balanço também merece atenção. Os resultados podem ajudar a tornar as próteses mais eficientes.

\section{Palavras-chave:}

Marcha humana. Subir e descer escadas. Cinemetria.

\begin{abstract}
Climbing and descending steps are activities that absorb a greater degree of difficulty, especially when it comes to an individual with musculoskeletal system alterations such as fractures in the lower limb. In view of the above problem, this study aims to analyze the human gait during climbing and descending of a healthy individual to indicate which parameters will be used and how they will be obtained for the prosthesis of lower limbs. Kinemetry models of motion, such as position and angular values of the body segments during gait, were analyzed from the kinematics, which were inserted in an algorithm in Matlab environment. It was possible to calculate the soil reaction forces to show the percentage of the gait cycle at each moment, to identify the periods, tasks and phases as well as to analyze the flexion and extension movements performed. The results suggest that in the development of a prosthesis it is necessary to worry about both the heel and the front of the foot, since it also receives a lot of weight from the body during the going up and down of steps, and that the phase of support to the balance phase also deserves attention. The results can help make prostheses more efficient.
\end{abstract}

\section{Keywords:}

Human gait. Up and down stairs. Kinemetry.

\section{Como você deve citar?}

LESSA, Luciana Moreira; GOUVÊA, Jayme Pereira. Análise biomecânica da marcha humana durante o subir e descer escadas. Cadernos UniFOA, Volta Redonda, n. 38, p. 21-36, dez. 2018. 


\section{INTRODUÇÃO}

Este trabalho enquadra-se num estudo mais amplo que está em curso, no qual se pretende desenvolver uma prótese de membro inferior, em particular a transtibial. Este estudo está sendo desenvolvido pelo Laboratório de Biomecânica, pertencente à Escola de Engenharia Industrial Metalúrgica de Volta Redonda.

A marcha humana é um dos assuntos mais estudados dentro da Biomecânica, motivado por curiosidade, necessidade ou constante evolução nos métodos e técnicas de investigação. Para Kuriki (2013), subir e descer escadas são atividades funcionais às quais os indivíduos são submetidos quase que diariamente para acessar determinados locais; e tal como a locomoção, fazem-no de maneira natural. Porém, quando se trata de um indivíduo com alterações do sistema musculoesquelético devido a fraturas no membro inferior, por exemplo, esses movimentos podem ser comprometidos, e o indivíduo pode apresentar dificuldades em realizá-los.

Durante a marcha, Enoka, (2000) explica que um dos pés está sempre em contato com o solo, e por um breve espaço de tempo, em cada ciclo, ambos os pés estão sobre o solo. Pode-se assim caracterizar a marcha como uma sequência alternada de apoio simples e duplo.

Por ser um ciclo repetitivo, a análise de apenas um ciclo permite a observação de todo evento. 0 ciclo da marcha é descrito em termos de percentagem, em vez de tempo decorrido, pois os eventos ocorrem em sequência bastante similar, independentemente do tempo (ROSE; GAMBLE, 1998). Na marcha do plano, padroniza-se que o tempo de apoio compreende $60 \%$ do total do ciclo e, o tempo de balanço, $40 \%$ do total do ciclo (Perry, 2005). Para a subida e descida da escada esses valores se alteram. Os períodos são divididos em três tarefas básicas: aceitação de peso, apoio simples e avanço do membro. A aceitação de peso inicia o período de apoio; o apoio simples dá seguimento ao apoio; e o avanço do membro começa na fase final do apoio. Cada uma dessas tarefas compreende algumas fases da marcha. Na tarefa de aceitação de peso, distinguem-se duas fases: o contato inicial do pé com a superfície e a resposta à carga. A tarefa de apoio simples compreende três fases: apoio médio, apoio terminal e pré-balanço. A terceira tarefa se relaciona à fase de avanço do membro e engloba as seguintes fases: pré-balanço, balanço inicial, balanço médio e balanço terminal (PERRY, 2005; ROSE; GAMBLE, 2006; WINTER, 1990). A Fig. 1 demonstra os períodos, tarefas e fases da marcha. 
Figura 1 - Períodos, tarefas e fases do ciclo da marcha na subida (A) e descida (B) da escada.

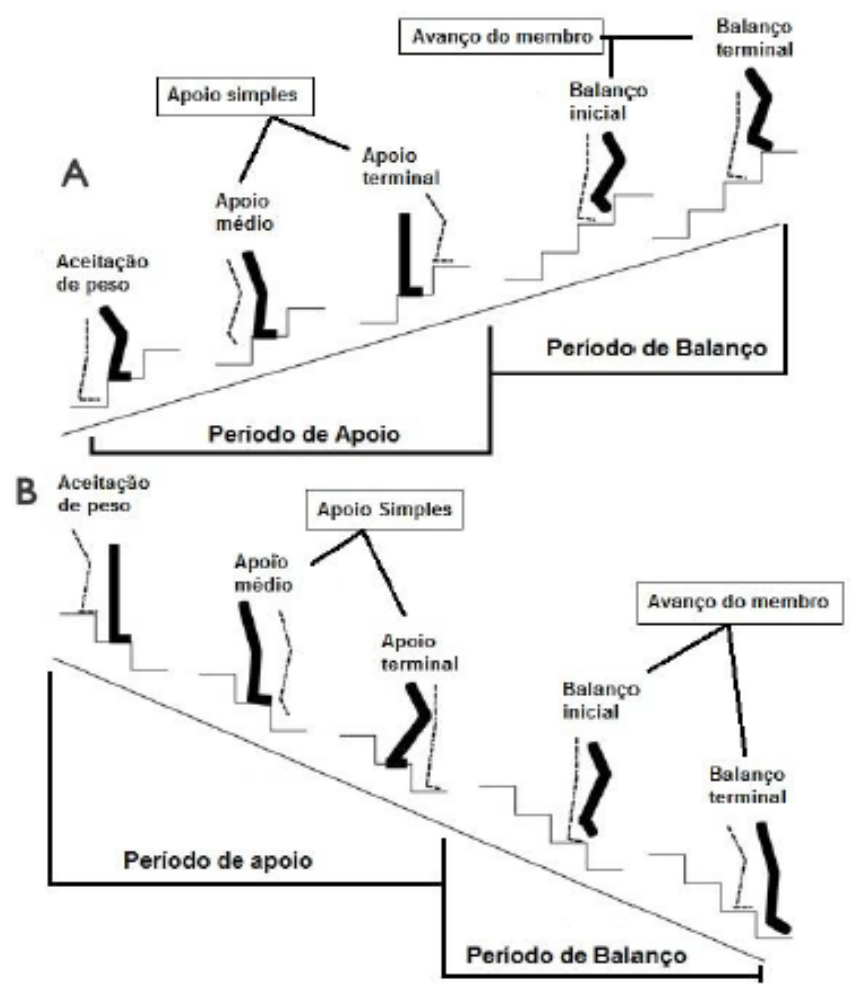

Fonte: Carli, J.V.M., 2013

Nas análises biomecânicas, os dados são divididos em dois grupos: cinética e cinemática. A cinética estuda as forças e momentos, mas sem qualquer conhecimento detalhado da posição ou orientação das estruturas envolvidas. A cinemática descreve o movimento, mas sem referência às forças envolvidas (Silva, 2011). É visível que, para uma adequada descrição quantitativa acerca do movimento humano, é necessária a conjugação e interligação de dados cinéticos e cinemáticos (WHITTLE, 2007).

As variáveis mais utilizadas na análise da marcha são as variações nos ângulos e momentos de força nas articulações do tornozelo, joelho e quadril. Porém, como o corpo humano é considerado um sistema articulado, qualquer movimento alterado em uma de suas partes afetará o resultado global da marcha (ANDRADE, 2002).

Diante do exposto, este estudo teve como objetivos determinar, a partir da Cinemetria: os ângulos articulares do indivíduo, as forças de reação do solo, a porcentagem do ciclo da marcha em cada instante, os períodos, tarefas e fases, os movimentos de flexão e extensão e os momentos gerados pelas forças de reação do solo durante a marcha humana no subir e descer de escadas, permitindo assim analisar as características funcionais da marcha humana durante os movimentos.

\section{MATERIAIS E MÉTODOS}

Para o estudo, é utilizado como base o modelo antropométrico proposto por Winter (1990) para a análise da marcha humana. Nesse modelo, o comprimento de cada segmento corporal é expresso em porcentagem da altura total do corpo $(H)$, enquanto a massa de cada segmento também é resulta- 
do da fração da massa corporal total (M). A Fig. 2 ilustra o comprimento de cada segmento do corpo humano em função da altura $\mathrm{H}$.

Figura 2 - Comprimento dos segmentos corporais em porcentagem da altura $\mathrm{H}$.

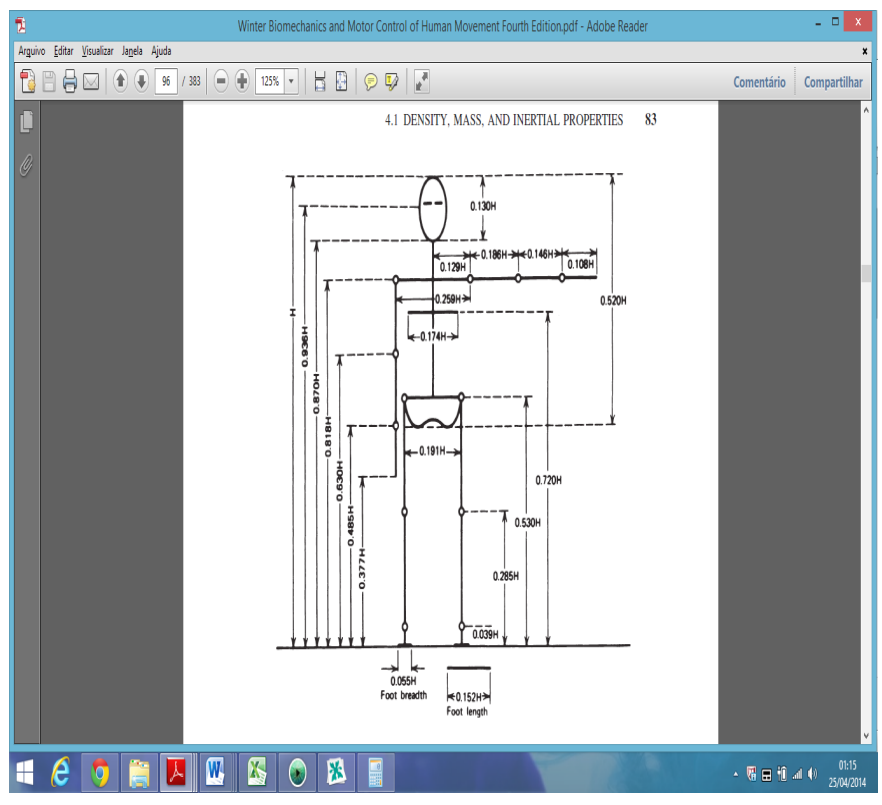

Fonte: WINTER, 1990.

O presente estudo interpreta o movimento da marcha segundo o plano sagital, considerando um modelo bidimensional composto por 14 regiões: cabeça, tronco, braço direito, braço esquerdo, antebraço direito, antebraço esquerdo, mão direita, mão esquerda, coxa direita, coxa esquerda, perna direita, perna esquerda, pé direito e pé esquerdo.

A estatura definida para o modelo é do sexo feminino, com 1,60m de altura e massa de $55 \mathrm{~kg}$. 0 comprimento e a massa de cada segmento corporal são calculados de acordo com as frações percentuais descrita por Winter.

\subsection{Procedimentos de coleta de dados}

Para definir e localizar os pontos anatômicos que delimitam cada um dos segmentos que constituem o modelo, utilizou-se marcadores passivos feitos de esferas de isopor de $15 \mathrm{~mm}$ de diâmetro e fixados nos centros articulares do corpo, como ombro, quadril, joelho, tornozelo, metatarso, cotovelo e metacarpo e também nos calcanhares.

Os movimentos dos membros corporais durante a execução da marcha foram filmados através de uma câmera de vídeo Samsung posicionada paralelamente ao indivíduo a uma distância de 2,5m e a $1 \mathrm{~m}$ de altura do solo, de forma a adquirir a imagem do plano sagital.

Durante a subida, o indivíduo inicia o movimento com o calcanhar direito, tocando o primeiro degrau e finaliza quando o mesmo toca o terceiro degrau. Na descida, o movimento se inicia quando a frente do pé direito toca o segundo degrau e finaliza quando o mesmo toca o solo, realizando assim o mesmo movimento descrito na Fig. 1.

A Fig. 3 ilustra os movimentos e os pontos anatômicos. 
Figura 3 - Movimento inicial e final do ciclo da marcha no subir e descer escadas e os pontos anatômicos.

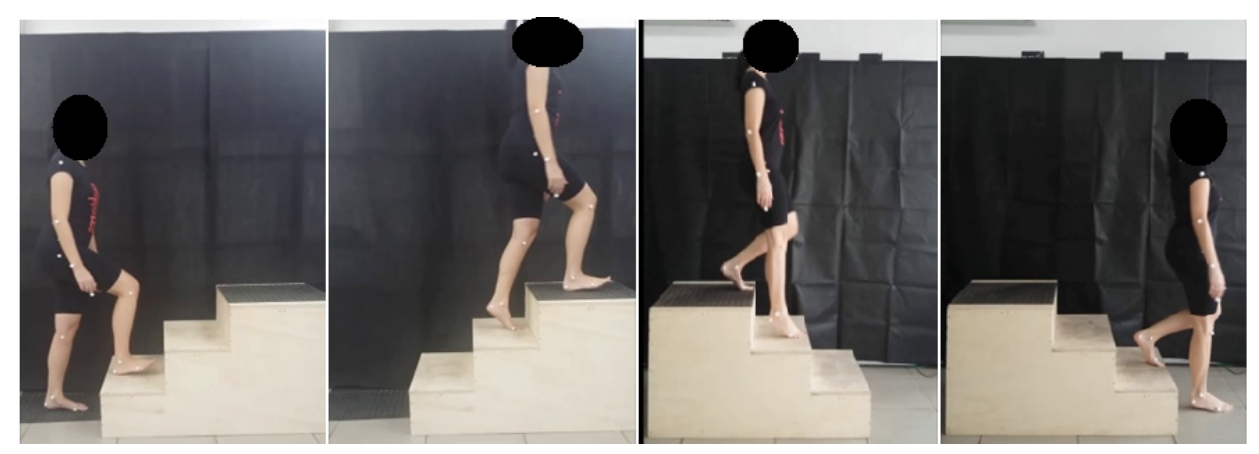

Fonte: dos autores, 2017.

A escada utilizada no estudo foi construída em madeira compensada e contém três degraus com espelho de $20 \mathrm{~cm}$, pisos de $30 \mathrm{~cm}$ e termina em um platô de $50 \mathrm{~cm}$. Após a filmagem, o vídeo é extraído para o software de domínio público Kinovea ${ }^{\circledR}$ versão 0.8 .24 , no qual primeiramente são adquiridos os ângulos que cada segmento corporal faz com o eixo vertical durante a marcha. 0 procedimento de aquisição dos ângulos é repetido em todos os segmentos corporais, braço, antebraço, mão, coxa, perna e pé durante todo o tempo da marcha tanto para a subida quanto para a descida de escadas. Logo após, são adquiridos os ângulos do tornozelo, que são formados através da articulação dos segmentos da perna e do pé. 0 procedimento também é repetido durante todo o movimento de forma que pode ser feita a análise dos movimentos de flexão e extensão do tornozelo. Em seguida, os vídeos são divididos em frames, para analisar separadamente cada quadro de imagem com seus ângulos, assim como determinar através das imagens os períodos, tarefas e fases, de acordo com a literatura. Todos os dados obtidos foram armazenados em tabelas no Excel.

Através de um algoritmo em ambiente Matlab desenvolvido são inseridos os ângulos encontrados juntamente com o peso e altura do modelo, o número de frames e o vetor situação, para calcular as forças de reação do solo e gerar os gráficos, onde será possível verificar a porcentagem do ciclo da marcha em cada frame, indicar em que momento do ciclo se encontram os períodos, tarefas e fases e analisar os movimentos de flexão e extensão do tornozelo sobre a ação muscular exercida e o momento gerado pelas forças de reação do solo, sendo permitido analisar qualitativamente e quantitativamente o padrão de marcha apresentado por um indivíduo saudável.

As forças de reação do solo foram calculadas através das equações de equilíbrio de corpos rígidos:

$$
\begin{aligned}
& \text { Fcalcanhar }+ \text { Fdedo }- \text { Fpeso }=0 \\
& \text { Fpeso.Xcm }- \text { Fdedo. } Y=0
\end{aligned}
$$

0 momento através da equação 3 :

$$
M=F . d
$$

Para identificar os períodos, tarefas e fases durante o ciclo, são utilizados os ângulos obtidos pelos movimentos de flexão e extensão do tornozelo. A Fig. 4 mostra a nomenclatura empregada. Para avaliar os movimentos de flexão e extensão, é considerada a diferença entre os ângulos do tornozelo, que é formado através da articulação dos segmentos da perna e do pé, e o ângulo da posição neutra ou posição de descanso (Fig.4). 
Figura 4 - Movimento de extensão e flexão com os ângulos articulares do tornozelo em um determinado instante de tempo e ângulo da posição neutra do indivíduo.

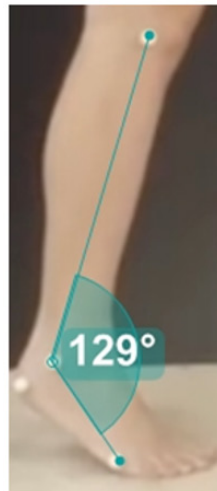

Extensão

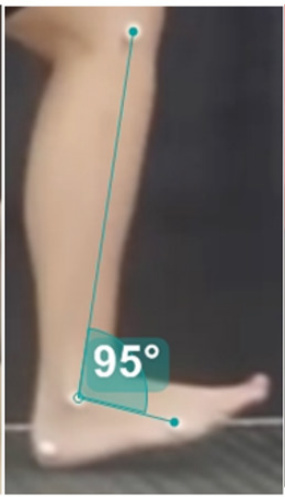

Flexão

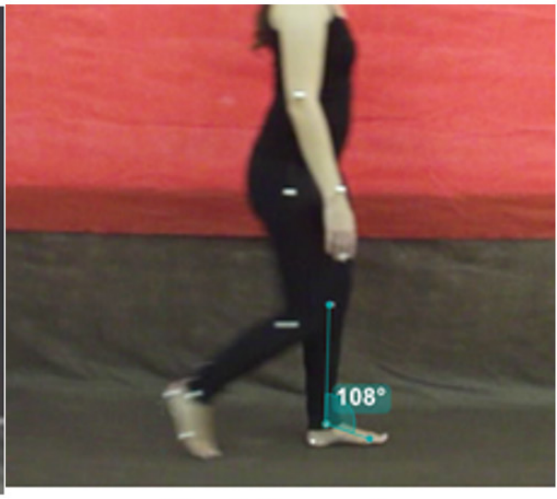

Posição neutra

Fonte: dos autores, 2017.

\section{RESULTADOS E DISCUSSÃO}

\subsection{Marcha no subir escadas}

O gráfico 1 apresenta o gráfico geral em percentuais do ciclo da marcha, das forças de reação vertical do solo, distribuídas entre calcanhar e frente do pé direito e esquerdo durante todo o ciclo da marcha.

Gráfico 1. Distribuição das forças de reação vertical em \% ciclo da marcha durante o subir escadas.

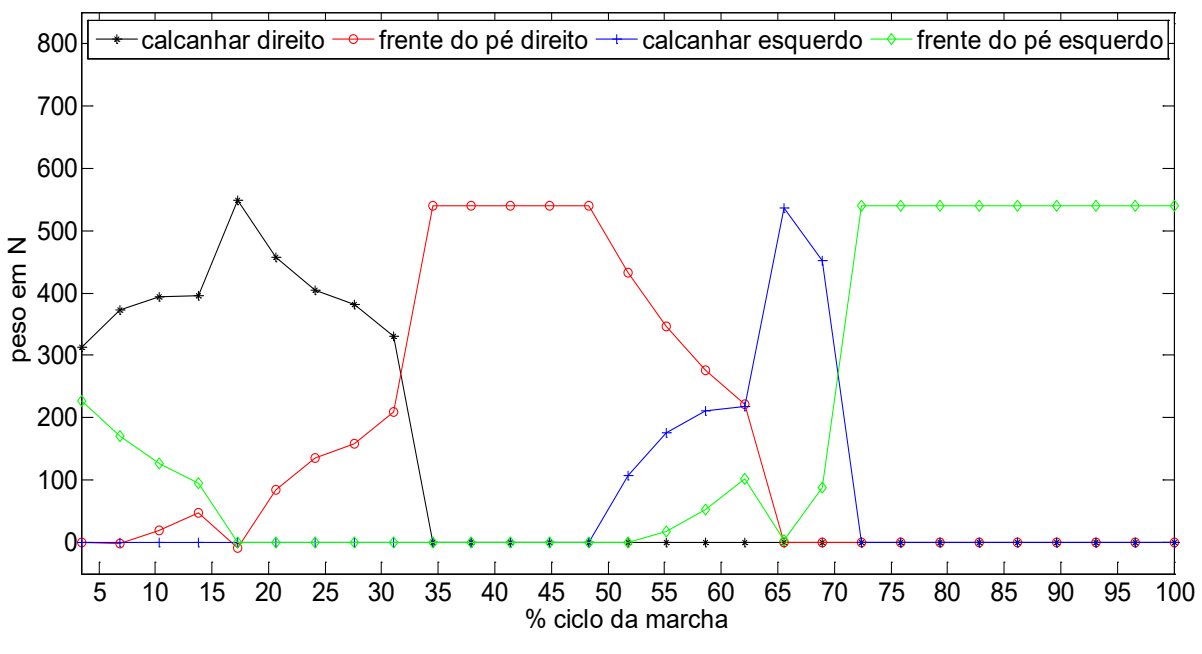

Fonte: dos autores, 2017.

O resultado obtido neste estudo é próximo do resultado apresentado por Zachazewski; Riley \& Krebs (1993). Os autores mencionam que $65 \%$ do ciclo é destinado ao período de apoio e $35 \%$ corresponde ao período de balanço durante a subida. Os resultados do estudo atual mostram que o calcanhar direito e a frente do pé direito estão presentes em aproximadamente $65 \%$ do ciclo da marcha, caracterizando o período de apoio. Logo após, entram no período de balanço por, aproximadamente, $35 \%$ do ciclo, dando espaço para o pé direito. 
As forças de reação do solo são caracterizadas por duas fases que se repetem a cada passo. Durante a subida, as FRS verticais se alteram suavemente, alcançando picos similares à marcha no plano, mas com um pouco de atraso temporal (RIENER; RABUFFETTI; FRIGO, 2002). 0 estudo atual conseguiu identificar o mesmo comportamento na FRS, conforme ilustra o Gráfico 2.

Gráfico 2 - Resultado dos somatórios das FRS verticais encontrado.

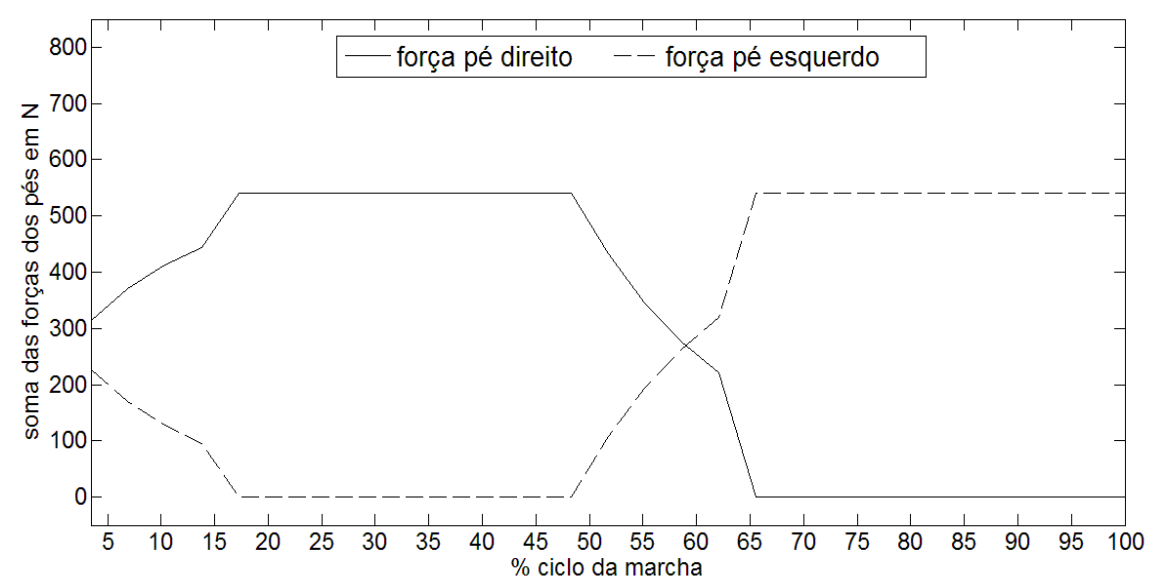

Fonte: dos autores, 2017.

A metodologia adotada neste estudo analisa o ciclo da marcha em equilíbrio, não levando em consideração a aceleração do corpo durante o movimento, a ação das forças internas presentes no corpo humano, a presença da força de impacto e da força de atrito existente no contato do pé com o solo. Por esse motivo, os resultados da distribuição das forças de reação do solo, ao invés de conterem dois picos e um vale no período de apoio simples, apresentam apenas uma linha constante, resultado do somatório das forças de reação do calcanhar e frente do pé, equivalente ao peso corporal. O resultado é parecido com da autora Pereira (2014), que utilizou a mesma metodologia adotada neste estudo. A autora calculou as forças de reação do solo nas regiões de contato do pé com a superfície e verificou a variação da intensidade dessas forças entre o calcanhar e os dedos do pé, sem a consideração das forças de atrito.

Para identificar os períodos, tarefas e fases durante o ciclo, são utilizados os valores obtidos pelos movimentos de flexão e extensão do tornozelo. 0 gráfico 3 apresenta os períodos e as fases que são discutidos separadamente. Os pontos sinalizados na figura são os frames que foram extraídos através do processo de cinemetria. 
Gráfico 3 - Identificação dos períodos, tarefas e fases da marcha no subir de escadas.

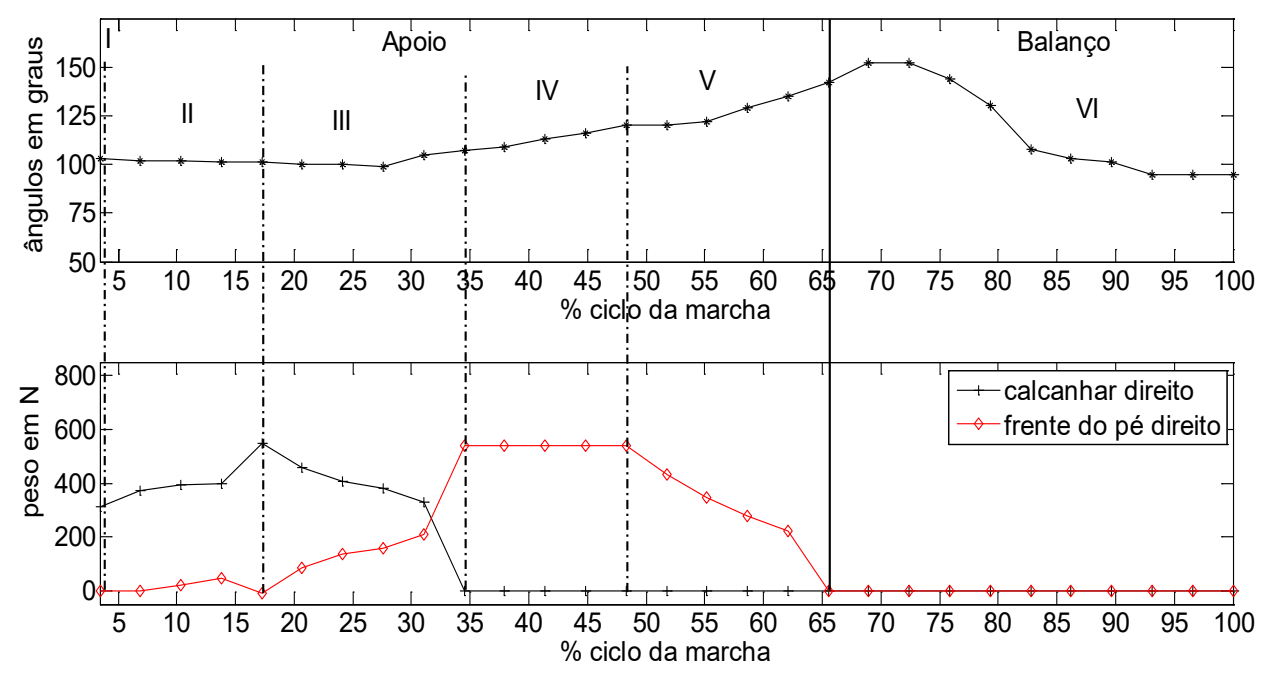

Legenda: I - contato inicial, II - resposta a carga, III - apoio médio, IV - apoio terminal, V - pré-balanço, VI - balanço inicial, médio e terminal

Fonte: dos autores, 2017.

A aceitação do peso é dividida em contato inicial e resposta à carga.

I - Contato inicial: o contato inicial na subida de escada se inicia no instante em que o pé direito toca o primeiro degrau, representado na Gráfico 3 pelo primeiro frame.

II - Resposta à carga: essa fase termina no quinto frame. Ela envolve o contato do pé com o primeiro degrau até a saída do outro pé do solo para o balanço.

Tarefa de apoio simples, dividida em apoio médio e apoio terminal.

III - Apoio médio: começa quando o outro pé é elevado e continua até que o peso do corpo seja alinhado sobre o antepé, terminando com a saída do calcanhar do solo do primeiro degrau. Essa tarefa situa-se no intervalo de 15 a $35 \%$ do ciclo, representado na figura pelo intervalo do quinto ao décimo frame.

IV - Apoio terminal: tem início na saída do calcanhar do solo do primeiro degrau até o toque do outro pé no segundo degrau, começando no décimo primeiro frame e terminando no décimo quarto frame. Corresponde um intervalo de 34 a $48 \%$ do ciclo.

$\mathrm{Na}$ tarefa de avanço do membro no período de apoio, temos a fase de pré-balanço; as demais se encontram no período de balanço.

V - Pré-balanço: compreende o intervalo do contato inicial do membro oposto no segundo degrau até a saída do pé de apoio do primeiro degrau, situando-se no intervalo de 48 a $66 \%$ do ciclo da marcha.

O período de balanço corresponde de 65 a 100\% do ciclo. 
VI - Balanço inicial, médio e terminal: são divisões da fase de balanço da perna, que se iniciam com a elevação do pé direito do primeiro degrau e finalizam com o toque do mesmo pé no platô do terceiro degrau.

Para a análise dos movimentos de flexão e extensão juntamente, o momento gerado pelas forças de reação do solo é considerado a diferença entre o ângulo do tornozelo e o ângulo da posição da posição neutra. A determinação dos momentos realizados pelas ações musculares durante o período de balanço não é finalidade deste estudo.

O Gráfico 4 apresenta os ângulos referentes aos movimentos de flexão e extensão sob a ação muscular exercida durante a marcha e o momento gerado pelas forças de reação do solo no período de apoio. Estão assinalados de vermelho os frames onde se encontram a flexão e extensão máximas, assim como o momento máximo.

Gráfico 4 - Movimentos de flexão e extensão do tornozelo e os momentos gerados pelas forças de reação do solo.

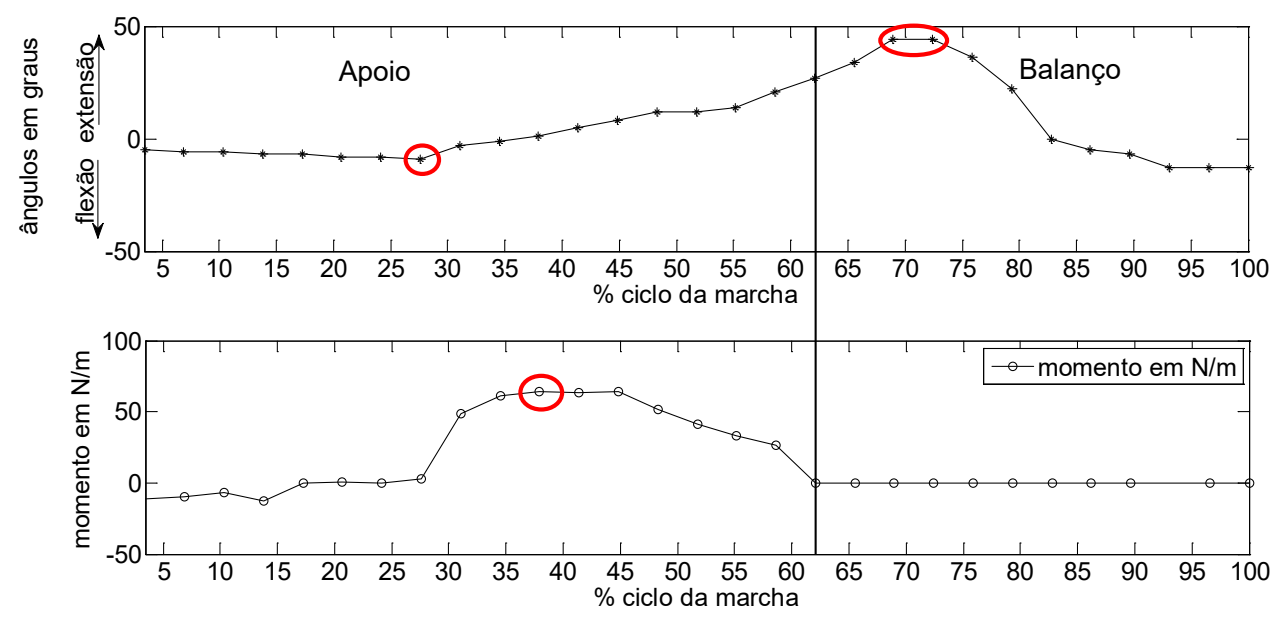

Fonte: dos autores, 2017

Na subida, o tornozelo inicia o período de apoio flexionado e se mantém flexionado durante toda a primeira metade do apoio. À medida que a marcha avança para a segunda metade do apoio, o tornozelo vai se estendendo cada vez mais até a fase de balanço inicial, onde atinge a extensão máxima, mas termina o movimento de balanço com maior flexão, devido à necessidade de posicionar o pé no degrau acima. Pode-se notar que a extensão é tão presente quanto à flexão, tanto no período de apoio quanto do período de balanço, a ação muscular do indivíduo que faz com que esse movimento seja possível. Na quadro 1, estão apresentados valores das variáveis analisadas. 
Quadro 1 - Valores das variáveis do tornozelo analisadas durante a marcha no subir escadas.

\begin{tabular}{|l|l|l|}
\hline Variável & Descrição & Valor \\
\hline Extensão máxima & $\begin{array}{l}\text { Valor da extensão máxima durante a movimentação da articulação do tornozelo } \\
\text { a partir da posição neutra. }\end{array}$ & $44^{\circ}$ \\
\hline Flexão máxima & $\begin{array}{l}\text { Valor da flexão máxima durante a movimentação da articulação do tornozelo a } \\
\text { partir da posição neutra. }\end{array}$ & $-9^{\circ}$ \\
\hline Amplitude articular & $\begin{array}{l}\text { Diferença entre flexão e extensão máximas do tornozelo durante o ciclo da } \\
\text { marcha. }\end{array}$ & $53^{\circ}$ \\
\hline Momento máximo & $\begin{array}{l}\text { Valor máximo do momento durante a movimentação da articulação do tornozelo } \\
\text { a partir da posição neutra. }\end{array}$ & $65,45 \mathrm{~N} / \mathrm{m}$ \\
\hline
\end{tabular}

Fonte: dos autores, 2017.

Carli (2013) analisou a marcha de idosos com diferentes níveis de funcionalidade na transição entre o terreno plano e a escada na subida e na descida. Participaram do estudo 34 idosos, divididos em dois grupos. Os resultados encontrados para as amplitudes das articulações do tornozelo variaram de $39^{\circ} \mathrm{a}$ $50^{\circ}$. Neste estudo, os deslocamentos angulares das articulações do tornozelo não revelaram diferenças entre os grupos experimentais e são similares aqueles reportados para jovens e idosos nos estudos de Andriacchi et al. (1980), Hortobágyi et al. (2003) e Riener et al. (2002). No estudo de Hortobágyi et al. (2003), os deslocamentos angulares de jovens e idosos também foram similares durante a subida.

\subsection{Marcha no descer de escadas}

O gráfico 5 ilustra, em percentuais do ciclo, as forças de reação vertical do solo distribuída entre calcanhar e frente do pé direito e esquerdo durante todo o ciclo.

Gráfico 5 - Distribuição das forças de reação vertical em \% ciclo da marcha durante o descer escadas.

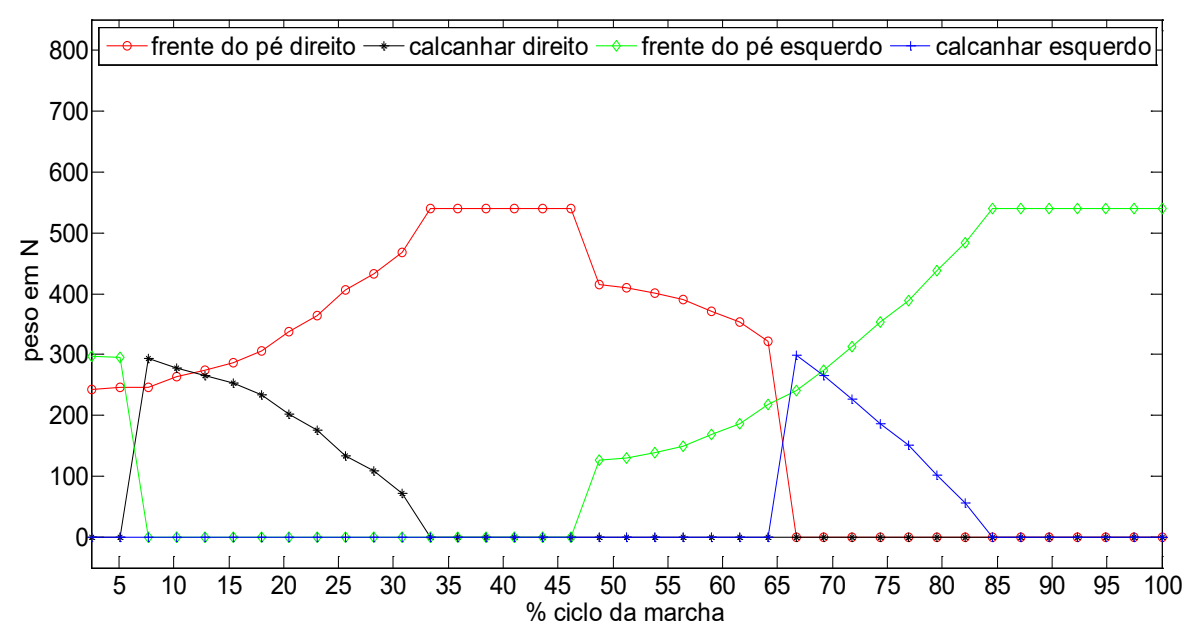

Fonte: dos autores, 2017.

Os resultados obtidos na descida também ficaram próximos dos resultados apresentados pelos autores Zachazewski; Riley \& Krebs (1993), que mostram a relação entre tempo de apoio e balanço de $68 \%-32 \%$, respectivamente. No estudo atual, o calcanhar e a frente do pé direito estão presentes em, 
aproximadamente, $68 \%$ do ciclo, representando o período de apoio e, aproximadamente, $32 \%$ do ciclo estão em fase de balanço.

O estudo de Christina e Cavanagh, (2002) analisou os efeitos da idade nas FRS e identificou que, na descida, o primeiro pico vertical é maior que na marcha no plano e o segundo pico é menor. Silva et al. (2014) verificaram a diferença na força vertical de reação do solo entre idosas com e sem preocupação com quedas na mobilidade durante a descida de escada e identificaram que o primeiro pico vertical é maior e o segundo pico é menor em relação à marcha em terreno plano. 0 resultado do somatório das forças de reação do calcanhar e frente do pé desta pesquisa mostra que, antes do final da fase de apoio, há uma queda na linha do somatório, conforme o Gráfico 6, o que pode indicar que se não houvesse as limitações impostas pelo presente programa utilizado, a curva do gráfico ficaria como a da literatura.

Gráfico 6 - Resultado dos somatórios das FRS verticais na descida de escadas encontrados.

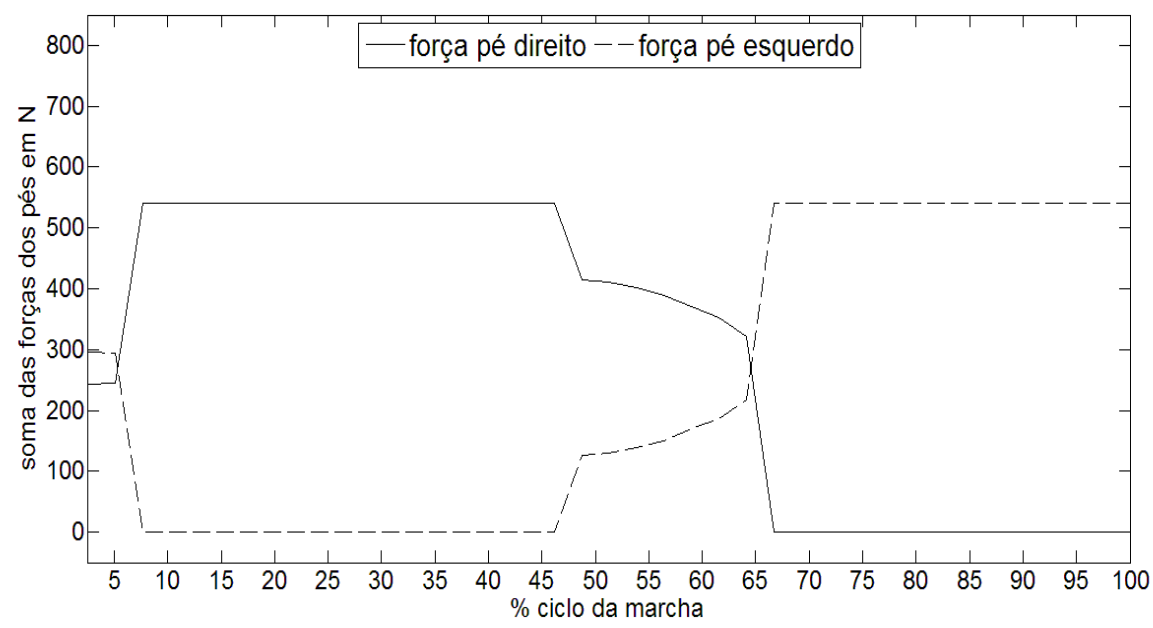

Fonte: dos autores, 2017. 
Os períodos, tarefas e fases da descida são apresentados no Gráfico 7.

Gráfico 7 - Identificação dos períodos, tarefas e fases da marcha no descer de escadas.

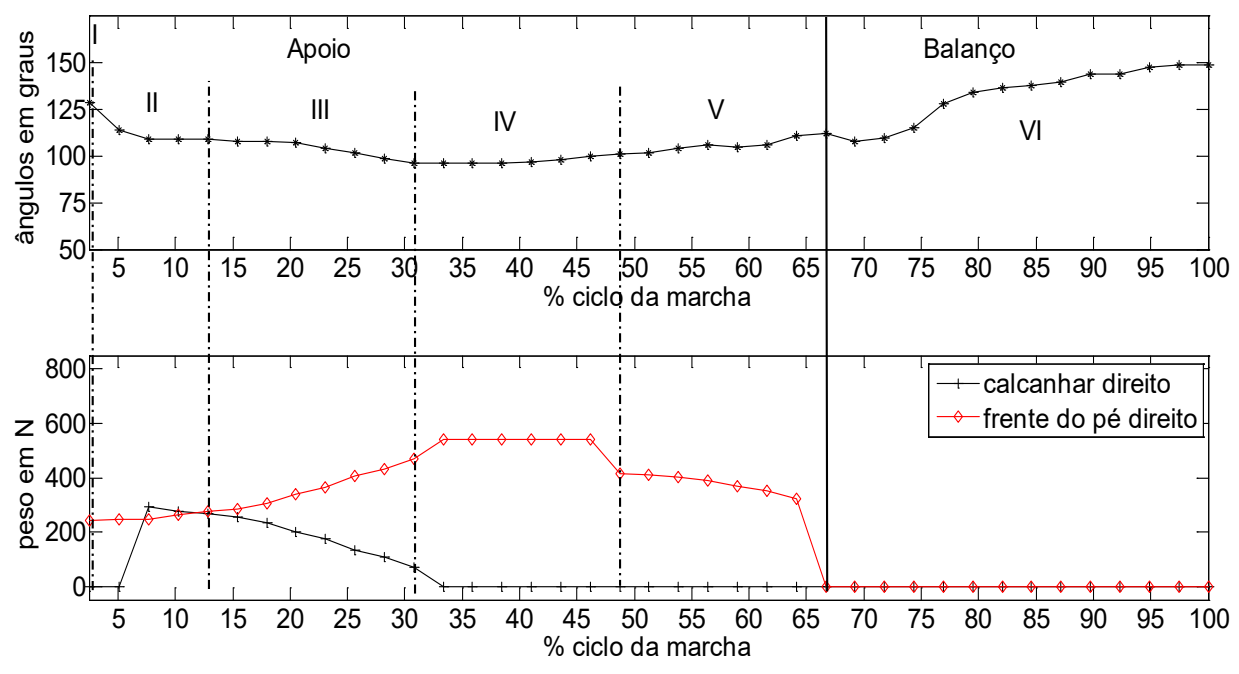

Legenda: I - contato inicial, II - resposta a carga, III - apoio médio, IV - apoio terminal, $\mathrm{V}$ - pré-balanço, $\mathrm{VI}$ - balanço inicial, médio e terminal

Fonte: dos autores, 2017.

Tarefa de aceitação do peso:

I - Contato inicial: se inicia no instante em que a frente do pé direito toca o segundo degrau, representado no Gráfico 7 pelo primeiro frame.

II - Resposta a carga: envolve o intervalo entre o contato da frente do pé com o segundo degrau até a saída do outro pé do platô para o balanço.

Tarefa de apoio simples:

III - Apoio médio: começa quando o pé esquerdo é elevado e continua até que o peso do corpo seja alinhado sobre a frente do pé direito, terminando com a saída do calcanhar do solo do segundo degrau.

IV - Apoio terminal: tem início na saída do calcanhar do solo do segundo degrau até o toque do outro pé no primeiro degrau; na figura, representa o intervalo do décimo segundo até o décimo nono frame.

Tarefa de avanço do membro no período de apoio:

V - Pré-balanço: Compreende o intervalo entre contato da frente do pé esquerdo no primeiro degrau até a saída do pé de apoio para o balanço. Compreende o espaço do décimo nono ao vigésimo sexto frame.

O período de balanço durante a descida de escadas corresponde de 68 a 100\% do ciclo. Se comparado com a subida é menor, pois na subida o balanço corresponde de 65 a 100\%. Essa diferença simula diferentes estratégias adotadas pelos indivíduos na intenção de realizar a tarefa de maneira segura. 
VI - Balanço inicial, médio e terminal: são divisões da fase de balanço da perna, que se iniciam com a elevação do pé direito do segundo degrau e finalizam com o toque da frente do mesmo pé no solo.

Durante o período de apoio na descida de escadas, a frente do pé é utilizada durante todo o movimento. 0 calcanhar é utilizado apenas em $35 \%$ do apoio. 0 movimento realizado na descida é diferente do movimento da subida, onde temos uma presença maior do calcanhar.

O Gráfico 8 apresenta os ângulos referentes aos movimentos de flexão e extensão sob a ação muscular e os momentos gerados pelas forças de reação do solo no período de apoio. Destacados de vermelho estão os frames onde se encontram a flexão e extensão máximas, assim como o momento máximo.

Gráfico 8 - Movimentos de flexão e extensão do tornozelo e os momentos gerados pelas forças de reação do solo.

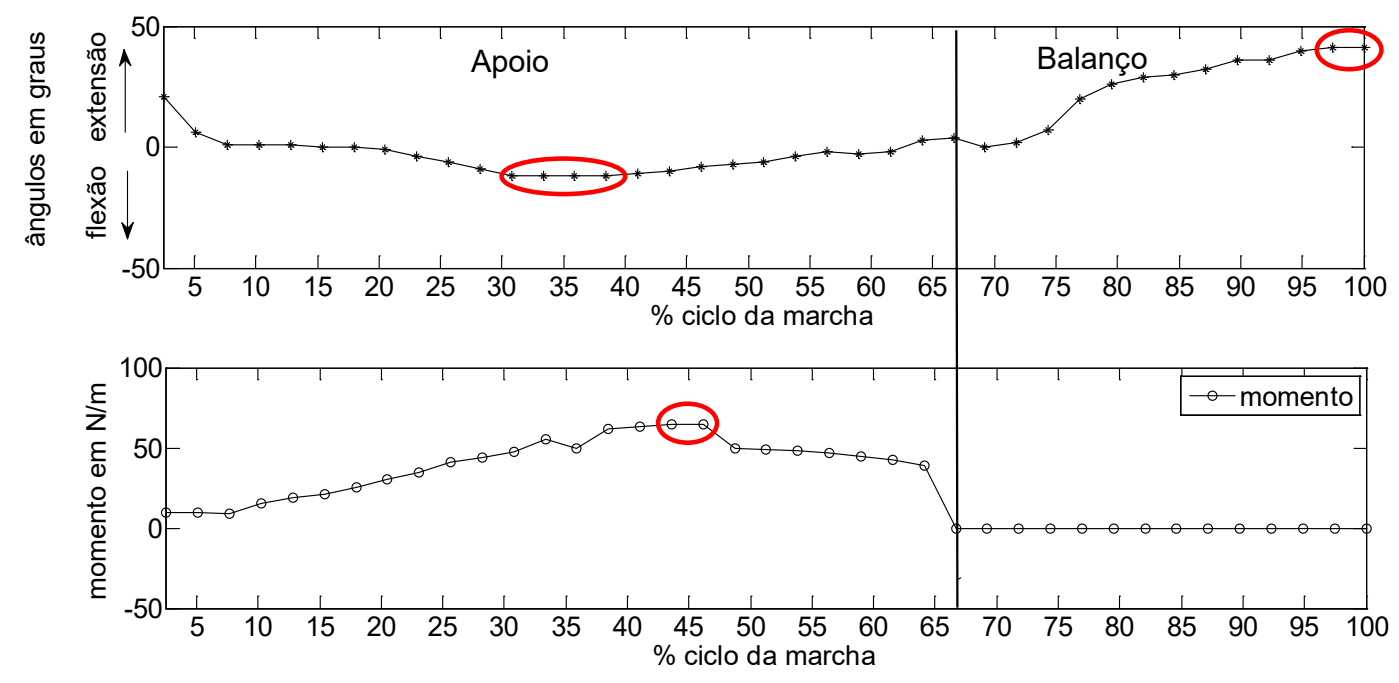

Fonte: dos autores, 2017.

Durante a descida, o tornozelo inicia o período de apoio estendido e logo se flexiona e se mantém flexionado durante quase todo o apoio. Somente no período de balanço, ele volta a apresentar o movimento de flexão, devido à necessidade de posicionar o pé no degrau abaixo. 
O quadro 2 apresenta os valores das variáveis analisadas.

Quadro 2 - Valores das variáveis do tornozelo analisadas durante a marcha.

\begin{tabular}{|l|l|l|}
\hline Variável & Descrição & Valor \\
\hline Extensão máxima & $\begin{array}{l}\text { Valor da extensão máxima durante a movimentação da articulação do tornozelo a } \\
\text { partir da posição neutra. }\end{array}$ & $41^{\circ}$ \\
\hline Flexão máxima & $\begin{array}{l}\text { Valor da flexão máxima durante a movimentação da articulação do tornozelo a } \\
\text { partir da posição neutra. }\end{array}$ & $-12^{\circ}$ \\
\hline Amplitude articular & $\begin{array}{l}\text { Diferença entre flexão e extensão máximas do tornozelo durante o ciclo de } \\
\text { marcha. }\end{array}$ & $53^{\circ}$ \\
\hline Momento máximo & $\begin{array}{l}\text { Valor máximo do momento durante a movimentação da articulação do tornozelo } \\
\text { a partir da posição neutra. }\end{array}$ & $64,8 \mathrm{~N} / \mathrm{m}$ \\
\hline
\end{tabular}

Fonte: dos autores, 2017.

Para a descida, Carli (2013) encontrou para as amplitudes das articulações do tornozelo valores entre $54^{\circ}$ e $87^{\circ}$. Também não foram reveladas diferenças entre os grupos experimentais. Alguns trabalhos relacionando jovens e idosos com a descida da escada encontraram similaridade entre os deslocamentos angulares. (HORTOBÁGYI et al., 2003; REEVES et al., 2008).

\section{CONCLUSÃO}

Os resultados deste estudo, nas condições experimentais utilizadas, indicam que as estratégicas biomecânicas são diferentes para subida e para descida de escadas, sendo possível também perceber diferenças, se comparado ao plano horizontal.

Em relação à distribuição das forças de reação vertical do solo e determinação dos períodos, tarefas e fases da marcha, foram encontrados valores bem próximos ao da literatura. Na subida de escada, o período de apoio representa $65 \%$ do ciclo enquanto o período de balanço, $35 \%$. A frente do pé realiza um esforço maior que o calcanhar, como forma de adaptação para impulsionar o corpo para frente, a fim de neutralizar o efeito da gravidade. Na descida, o apoio representa $68 \%$ e o balanço $32 \%$; o calcanhar aparece no início do apoio, porém logo abre espaço para frente do pé, que é responsável por quase todo o movimento.

Para os movimentos de extensão e flexão do tornozelo, percebe-se que, na subida e descida, a amplitude dos movimentos é igual, chegando a $53^{\circ}$. Porém, exercem atuações um pouco diferentes, quando analisados os picos máximos e mínimos. A extensão máxima na subida chega a $44^{\circ}$ e a flexão máxima a $-9^{\circ}$. Essa inconsistência pode ser explicada devido ao fato de que na subida há uma maior demanda de atividade dos músculos que trabalham para impulsionar o corpo para cima. Na descida, o movimento de flexão prevalece durante todo o apoio. Somente no balanço que o movimento de extensão aparece, a extensão máxima é de $41^{\circ}$ e a flexão máxima de $-12^{\circ}$. Essa diferença entre os valores máximos pode ser creditada ao fato de que, na descida, o indivíduo precisa ter um controle descendente do corpo durante o apoio, de forma que não provoque uma queda.

No período de balanço, aparecem as extensões máximas para os dois movimentos analisados. A atividade de extensão aumenta de intensidade ao longo do balanço inicial na subida para ajudar a trazer a articulação do tornozelo para uma posição neutra, em que é mantido até o próximo contato inicial. Já na descida, a extensão máxima aparece na fase de balanço final, de modo a acomodar a frente do pé no degrau abaixo. 


\section{REFERÊNCIAS}

ANDRADE, L.M. Análise da Marcha: protocolo experimental a partir de variáveis cinemáticas e antropométricas. 2002. 93 f. Dissertação (mestrado) - Universidade Estadual de Campinas, Faculdade de Educação Fisica, Campinas, SP. Disponível em: <http://www.repositorio.unicamp.br/handle/ REPOSIP/275358>. Acesso em: 2 ago. 2017.

ANDRIACCHI, T. P.; ANDERSSON, G. B.; FERMIER, R. W.; STERN, D.; GALANTE, J. O. A study of lower-limb mechanics during stair-climbing. The Journal of Bone and Joint Surgery, v. 62, n. 5, p. 749-757, 1980.

CARLI, J.V.M. Análise da marcha de idosos com diferentes níveis de funcionalidade na transição entre o terreno plano e a escada. 2013. 94 f. Dissertação (Mestre em Educação Física) - Universidade Federal do Paraná, Curitiba, 2013.

CHRISTINA, K. A; CAVANAGH, PETER R. Ground reaction forces and frictional demands during stair descent: effects of age and illumination. Gait \& Posture, v. 15, n. 2, p. 153-158, 2002.

ENOKA, Roger M. Bases neuromecânicas da cinesiologia. 2. ed. São Paulo: Manole, 2000. 450 p.

HORTOBÁGYI, T., MIZELLE, C.; BEAM, S.; DEVITA, P. Old adults perform activities of daily living near their maximal capabilities. The journals of gerontology. Series A, Biological sciences and medical sciences, v. 58, n. 5, p. M453-60, 2003.

KURIKI, H.U. Caracterização de parâmetros biomecânicos durante a subida de degraus. 2013. 75 f. Tese (Doutorado) - Programa de Pós-Graduação Interunidades Bioengenharia (EESC /FMRP/IQSC), Universidade de São Paulo, São Carlos, 2013.

PEREIRA, F. F. V. Determinação do centro de massa corporal e das forças de reação do solo durante a marcha humana através das equações de equilíbrio. 2014. 78 f. Dissertação (Mestre em Engenharia Mecânica) - Escola de Engenharia Industrial Metalúrgica de Volta Redonda, Volta Redonda, 2014.

PERRY, Jacquelin. Análise de Marcha. Vol. 1. Marcha Normal. Barueri, SP. Manole, 2005.

REEVES, NEIL D; SPANJAARD, MARCEL; MOHAGHEGHI, A. A; BALTZOPOULOS, VASILIOS; MAGANARIS, CONSTANTINOS N. The demands of stair descent relative to maximum capacities in elderly and young adults. Journal of electromyography and kinesiology: official journal of the International Society of Electrophysiological Kinesiology, v. 18, n. 2, p. 218-27, 2008.

RIENER, R.; RABUFFETTI, M.; FRIGO, C. Stair ascent and descent at different inclinations. Gait \& posture, v. 15, n. 1, p. 32-44, 2002.

ROSE, Jessica; GAMBLE, James. G. Marcha Humana. 2. ed. São Paulo: Editorial Premier, 1998. 280 p.

ROSE, Jessica; GAMBLE, James G. Human walking. 3. ed. Baltimore: Williams \& Wilkins, 2006. 234 p.

SILVA, A.F.F. Avaliação de marcha e Postura em Reabilitação. 2011. Dissertação de mestrado. Faculdade de Engenharia da Universidade do Porto, Porto, 2011.

SILVA, D. O. et al. Influência da preocupação com quedas na mobilidade e na força de reação do solo em idosas durante descida de escada. Scientia Medica. v. 24, n 4, p361-367, 2014. 
WHITTLE, M. W. Gait analysis introduction. Oxford Boston, Butterworth Heinemann. 2007.

WINTER, D. A. Biomechanics and motor control of human movement. 2. ed. Waterloo: University of Waterloo Press, 1990.

ZACHAZEWSKI, J. E.; RILEY, P. O.; KREBS, D. E. Biomechanical analysis of body mass transfer during stair ascent and descent of healthy subjects. Journal Of Rehabilitation Research And Development, $v$. 30, n. 4, p. 412-22, 1993. 